УДК 622.279 .4

DOI: https://doi.org/10.26642/ten-2019-2(84)-149-155

К.С. Сай, к.т.н.

П.Б. Саїк, к.т.н.

В.Г. Лозинський, к.т.н.

М.В. Петльований, к.т.н.

Національний технічний університет "Дніпровська політехніка»

\title{
Дослідження термодинамічних умов формування гідратів генераторного газу
}

У иій роботі розглянуто проблеми, щуо виникають при впровадженні технології підземної газифікації при розробиі вугільних родовищ, зокрема з транспортуванням отриманого генераторного газу. Запропоновано перспективний напрям транспортування генераторного газу у вигляді газових гідратів, щяо скорочує систему промислових і магістральних газопроводів.

Аналітичними дослідженнями вдосконалено рівняння Клаузіуса-Клапейрона для умов формування газових гідратів, щзо враховує наявність надлишку нерівноважних дефектів у фазі 1 $($ лід + газ $\rightarrow$ тверда фаза) , щчо перетворюється у фазу 2 (вода + газ $\rightarrow$ рідка фаза). При ичьому це рівняння доповнене врахуванням теплового ефекту фазових перетворень (тепловим ефектом релаксачії дефектів). Суттєве підвищення внутрішньої енергії у вихідному перед фазовими перетвореннями стані газогідрату є накопичення в ньому граничних концентрацій різних дефектів та пустот.

Отримання гранично нерівноважних структур у вихідних речовинах за рахунок накопичення у них різного роду нерівноважних пустот, які пов'язані зі збільшенням швидкості теплопередачі, $\epsilon$ одним із напрямів активізащії процесу протікання фазових змін. Визначено, щчо енергія релаксаиії дефектів є термодинамічним стимулом фазових перетворень $i$ твердофазних реакиій, якими можна керувати. Для одночасного зниження температури $і$ тиску необхідне одночасне швидке нагрівання й збільшення тиску.

Ключові слова: газовий гідрат; генераторний газ; тепловий ефект; рівняння КлаузіусаКлапейрона; фазові перетворення; термодинамічні умови.

Постановка проблеми. Світове та європейське наукове співтовариство, зокрема ще у 80 -х роках XX століття після енергетичної кризи усвідомило, що природні ресурси не мають ставити під загрозу світову економічну стабільність [1]. У той самий час широко поширилася концепція розвитку паливноенергетичного сектору. Вугілля та інші викопні види палива 3 кожним роком все менше впливають на енергетичну безпеку країн, що розвиваються, у зв'язку із використанням альтернативних технологій генерації електроенергії та видобутку енергоресурсів [2, 3]. Сьогодні, враховуючи потенціал комплексної переробки наявних ресурсів, активне інвестування спостерігається у проекти, що спрямовані на сучасні безвідходні технології, функціонування яких відбувається в замкнутому екологічно безпечному циклі [4]. Що стосується формування енергохімічних систем на базі гірничодобувних підприємств, то широко були проведені великомасштабні пілотні дослідження щодо можливості впровадження альтернативних технологій отримання хімічної та теплової енергії на базі газифікації вугілля [5]. Основним енергетичним продуктом при газифікації вугілля є генераторний газ [6]. При цьому його транспортування до газосховищ та/або розподільчих газових пунктів потребує будівництва промислових і магістральних сухопутних газопроводів, що разом складають газотранспортну систему. Тому авторами роботи за основу розвитку нетрадиційних технологій розробки вугільних родовищ приймається технологія газифікації вугілля 3 подальшою можливістю транспортування генераторного газу у вигляді газових гідратів.

Аналіз останніх досліджень і публікацій. Керуючись науковими принципами створення сучасних систем комплексного освоєння енергетичних ресурсів, все частіше науковцями пропонується об'єднувати всі процеси та операції, що пов'язані з отриманням та переробкою цільових продуктів, в єдину технологічну систему [7].

За останнє десятиріччя низка досліджень приділена умовам формування газових гідратів при розробці природних родовищ газогідратів та газу $[8,9]$. При цьому дослідження термодинамічних умов базувалися на врахуванні основних класичних законів термодинаміки, що унеможливлюють оцінку характеру формування та дисоціації гідратів генераторного газу за фазами: лід + газ $\rightarrow$ тверда фаза, вода + газ $\rightarrow$ рідка фаза.

У відомих способах отримання газових гідратів $[10,11]$ основна увага приділялася встановленню максимальної швидкості гідратоутворення та активізації центрів кристалізації газового гідрату. Таким чином, метою роботи є дослідження термодинамічних умов отримання гідратів генераторного газу для обгрунтування фазових перетворень у твердих фазах при гідратоутворенні й розкладанні. 
Методика проведення досліджень. Аналітичні дослідження умов формування газових гідратів базувалися на врахуванні основних класичних законів термодинаміки. Дослідження грунтувалися на загальній статистичній моделі опису властивостей клатратних з'єднань, розробленій Ван-дер-Ваальсом, та на іiї вдосконаленнях у подальших роботах науковців, які її поширили на газові гідрати, описали та доповнили. Згідно з рівнянням Клаузіуса-Клапейрона поведінка газових гідратів під тиском також буде різною - від дестабілізації гідратів структури КС-ІІ до суттєвої стабілізації гідратів структури КС-I. Враховувалася наявність різних пустот у твердій фазі газогідрату, рівноважна концентрація яких неоднакова й визначається відповідно до величини їх енергії утворення. Для з'ясування залежності умов фазових перетворень від надлишку нерівноважних дефектів розглядалося два випадки, в яких фаза $1-$ тверда (лід + газ), а фаза 2 - рідка (вода + газ). Далі шляхом виконання ряду математичних перетворень отримується нове рівняння Клаузіуса-Клапейрона для умов формування газових гідратів, що враховує наявність надлишку нерівноважних дефектів.

Дослідження термодинамічних процесів при утворенні газових гідратів. На сьогоднішній день, завдяки методам статистичної термодинаміки, можна скласти повний опис фізико-хімічних властивостей газових гідратів, володіючи при цьому даними про характер сил взаємодії між молекулами у газогідратному кристалі та враховуючи інформацію про структуру газогідрату. Статистична модель для опису властивостей клатратних з’єднань гідрохінону була створена Ван-дер-Ваальсом. Потім ця модель була узагальнена на газові гідрати й описана та доповнена у подальших роботах науковців. Рівняння, які отримані у цих роботах, дають можливість визначити ступінь заповнення кристалічної решітки газового гідрату, i, відповідно, умови його утворення, а також склад. Ці рівняння можуть бути визначені, коли відомо відношення тиску парів води над чистою водою, водним розчином або льодом, які знаходяться у рівновазі з газовим гідратом, до тиску парів води над порожньою газогідратною решіткою як функція температури; або різниця хімічного потенціалу води, водного розчину або льоду, які знаходяться у рівновазі з газовим гідратом, і хімічного потенціалу води у порожній газогідратній решітці як функція температури і тиску, а також константа Ленгмюра як функції температури.

Процес гідратоутворення здійснюється таким чином:

$$
\mathrm{M}+n \mathrm{H}_{2} \mathrm{O} \rightarrow \mathrm{M} \cdot n \mathrm{H}_{2} \mathrm{O}+\Delta \mathrm{H}
$$

де $\Delta H$ - ентальпія утворення газогідрату.

Для реалізації та протікання цього процесу необхідним є виконання кількох обов'язкових умов. Поперше, молекула газу-гідратоутворювача має відповідати таким вимогам:

- мати гомеополярне походження;

- розміри і молярний об'єми гідратоутворювача мають бути обмежені;

- не утворювати водневих містків, а отже, погано розчинятися у воді;

- теплота випаровування гідратоутворювача має бути менше 7500 кал/моль, а точка кипіння - не перевищувати $60^{\circ} \mathrm{C}$.

По-друге, невід'ємними є такі термодинамічні умови:

- тиск насиченої пари води над рідкою водою або льодом має бути більшим, ніж рівноважний тиск парів води над газогідратним кристалом при такій температурі;

- тиск насиченої пари чистого газу- гідратоутворювача має бути більшим, ніж рівноважний тиск парів гідратоутворювача над твердим газогідратом.

Основні властивості газових гідратів (щільність $\rho$, теплоємність $c$, теплопровідність $\lambda$ ), а також умови їх утворення встановлюють експериментально, проте нестабільність цих сполук при атмосферному тиску і температурах вище $0{ }^{\circ} \mathrm{C}$ та їх нестехіометричність викликають певні складнощі при проведенні лабораторних досліджень $[12,13]$. Приблизні значення зазначених властивостей можливо отримати розрахунковими методами. При визначенні характеристик газових гідратів, утворених з різних газових сумішей, і природного газу в тому числі, їх точність може дещо відрізнятися від еталонного значення.

Головною особливістю водних клатратних каркасів $є$ те, що вони складаються 3 двох різних типів порожнин - малих $(D)$ і великих $(T, P, H, E)$. При цьому для стабільності та стійкості структури (при не досить низьких температурах) малі порожнини можуть бути частково вільними або навіть повністю вакантними, у той час як великі порожнини навпаки мають бути практично усі повністю зайняті. Оскільки відношення малих порожнин до великих у різних гідратних структурах коливається в широких межах $2>R_{t}>0$ (у тих випадках, коли малі $D$-порожнини залишаються вільними), то коефіцієнти упаковки газових гідратів, що утворюються, для різних структур будуть значно відрізнятися один від одного [14]:

$$
0,47<k<0,60, \text { звідки } k=\frac{\sum v_{i}}{V},
$$

де $\Sigma v_{i}$-сумарний об’єм усіх молекул, які складають фазу з об’ємом $V$. Тоді, згідно 3 рівнянням Клаузіуса-Клапейрона: 


$$
\frac{d T}{d P}=\frac{T \cdot \Delta V}{\Delta H},
$$

де $T$ - абсолютна температура; $P$ - тиск; $\Delta V$ і $\Delta H$ - зміна об'єму та ентальпії у реакції розкладання газогідрату), поведінка газових гідратів під тиском також буде різною - від дестабілізації гідратів структури КС-ІІ до суттєвої стабілізації гідратів структури КС-I.

Опираючись на існуючі дані [15], при температурі вище $0{ }^{\circ} \mathrm{C}$ у твердій фазі речовини завжди є різні пустоти, рівноважна концентрація яких неоднакова й визначається відповідно до величини їх енергії утворення таким шляхом:

$$
C=\frac{n}{N} \alpha e^{-\frac{E}{R T}},
$$

де $n$ - кількість пустот; $N$ - сумарне число атомів у кристалі; $\alpha$ - коефіцієнт, що враховує ступінь хаотичності у кристалі при утворенні пустот; $e$ - основа натурального логарифма, $e \approx 2,72 ; E$ - енергія утворення пустот; $R$ - універсальна газова постійна; $T$ - температура існування утворених пустот.

Під високим тиском утворення пустот у твердій фазі під дією сил стиснення у газогідратному кристалі знижується відповідно до такого виразу [16]:

$$
C_{P}=C\left(1-\frac{P V}{R T}\right),
$$

де $C$ - концентрація утворених пустот у кристалі при звичайних умовах; $P$ - величина прикладеного тиску; $V$ - об’єм одного моля пустот у кристалі; $R$ - універсальна газова постійна; $T$ - температура існування утворених пустот.

У міру наближення до високого тиску пружна енергія, порівняна 3 енергією утворення пустот, наближається за величиною до модуля нормальної пружності $\left(E \approx 10^{6}\right.$ атм). При цьому концентрація пустот у твердому тілі значно знижується. В першу чергу зменшиться концентрація дислокацій, потім локацій i, як наслідок, відбудеться «заморожування» дифузійних процесів [17]. Фазові зміни, які засновані на дифузійному механізмі спонтанного зародження й росту нової фази, теж почнуть сповільнюватися або стануть практично нездійсненними через сповільнену кінетику перетворення [18].

За умови, коли пружна енергія стиснення кристалічної решітки порівняна 3 енергією утворення міжвузлових атомів, ймовірність дифузії атомів по міжвузловинам, згідно зі щілинним механізмом протікання процесу, є надзвичайно низькою через стрімке зростання енергії активації дифузії атомів по міжвузловинам. Отже, протікання процесів фазових змін утруднено в твердих фазах при великих навантаженнях дією факторів, що виникають внаслідок цих навантажень. Для розвитку фазових перетворень за відносно короткий час при великих навантаженнях необхідним $\epsilon$ пошук способів їх активізації. Отримання гранично нерівноважних структур у вихідних речовинах за рахунок накопичення у них різного роду нерівноважних пустот, які пов'язані зі збільшенням швидкості теплопередачі, є одним із напрямів активізації процесу протікання фазових змін.

3 існуючих даних про граничні концентрації та енергію утворення пустот у твердих фазах випливає, що у кристалічній решітці масивних зразків металів можна отримати одне порушення решітки на $10^{3}, \mathrm{y}$ напівпровідниках, іонних кристалах і діелектриках - на $10^{6}$, а у тонких плівках - на 20-30 атомів. Такі стани вважаються нерівноважними. Релаксація дефектів з утворенням надлишкової енергії у вигляді позитивного теплового ефекту, як правило, відбувається при нагріванні. Явище релаксації дефектів пов'язують 3 рекристалізацією й поверненням [19]. При рекристалізації відбувається перерозподіл дислокацій зі зменшенням їх середньої концентрації. Тепловий ефект повернення не менший за тепловий ефект рекристалізації і становить для різних матеріалів від 0,1 до 0,7 усього теплового ефекту. Виділення тепла при поверненні розтягується на більш широкий інтервал температур, у той час як при рекристалізації виникнення зародків нових зерен і їх зростання відбуваються у більш вузькому інтервалі температур ( $\left.T_{\text {рекр }} \approx 0,4 T_{\text {плавл }}\right)$ i схожі з процесами, що мають місце при фазових перетвореннях.

У разі розгляду фазових переходів у газогідраті вплив на початковий стан фази 1 (лід + газ $\rightarrow$ тверда фаза), яка перетворюється у фазу 2 (вода + газ $\rightarrow$ рідка фаза), можна представити як вплив на іiі внутрішню енергію $U$ і узагальнені сили $X_{i}$, використовуючи відоме рівняння термодинаміки [19]:

$$
Z=U+\sum_{i} X_{i} L_{i},
$$

де $L_{i}-$ ізобарний потенціал переходу з одного фазового стану в інший.

Одним із головних факторів термодинамічного вивчення фазових перетворень за участю пустот, що утворюються, є той факт, що енергія їх релаксації завжди позитивна і може бути визначена калориметрично. Зміна термодинамічного потенціалу під впливом енергії релаксації утворених пустот також є позитивною.

Для з'ясування залежності умов фазових перетворень від надлишку нерівноважних дефектів порівняємо два випадки, в яких фаза 1 - тверда (лід + газ), а фаза 2 - рідка (вода + газ) [19]: 
- фаза 1, так само як і фаза 2, містить рівноважну концентрацію пустот у момент фазового перетворення;

- вихідна фаза 1 має в собі нерівноважні пустоти, концентрація яких у граничному надлишку умовно зберігається до часу фазового переходу фази 1 у фазу 2.

У першому випадку термодинамічний потенціал фази 1 і фази 2 визначимо таким чином:

$$
\begin{aligned}
& Z_{1}=U_{1}-T S_{1}+P V_{1}, \\
& Z_{2}=U_{2}-T S_{2}+P V_{2},
\end{aligned}
$$

де $U_{1}$ і $U_{2}$ - внутрішня енергія першої і другої фаз відповідно; $T$ - температура; $S_{1}$ і $S_{2}$ - ентропія першої і другої фаз відповідно; $P$ - величина прикладеного тиску; $V_{1}$ і $V_{2}-$ об’ $є$ м першої і другої фаз відповідно.

3 умови рівноваги

$$
Z_{1}=Z_{2} \text { i } \Delta Z=0
$$

слідує:

$$
\Delta U-T \Delta S+P \Delta V=0,
$$

де $\Delta$ показує зміни внутрішньої енергії та термодинамічних потенціалів на макрорівні:

$$
\begin{aligned}
& \Delta U=U_{2}-U_{1} \\
& \Delta S=S_{2}-S_{1} ; \\
& \Delta V=V_{2}-V_{1} .
\end{aligned}
$$

Тоді, рівноважна температура буде дорівнювати:

$$
T_{\text {рівн. }}=\frac{\Delta U+P \Delta V}{\Delta S} .
$$

У другому випадку, коли на утворення пустот витрачається енергія і тверда фаза розупорядковується, термодинамічні характеристики фази 1 змінюватимуться таким чином:

$$
\begin{aligned}
& U_{1}^{\prime}=U_{1}-\delta U_{1} ; \\
& S_{1}^{\prime}=S_{1}-\delta S_{1} ; \\
& V_{1}^{\prime}=V_{1}-\delta V_{1},
\end{aligned}
$$

де $\delta$ - мізерно мала зміна внутрішньої енергії та термодинамічних потенціалів, що відбуваються на мікрорівні. Відповідно:

$$
\begin{aligned}
& T_{\text {рівн. }}=\frac{\Delta U+\delta U+P \Delta V+P \delta V}{\Delta S+\delta S}, \\
& \text { де } \delta U=\delta U_{1}-\delta U_{2} ; \\
& \delta S=\delta S_{1}-\delta S_{2} \\
& \delta V=\delta V_{1}-\delta V_{2} .
\end{aligned}
$$

Зміщення температури рівноваги $\Delta T^{\prime}=T^{\prime}-T$ після підстановки значень $T^{\prime}$ і $T$ з рівнянь (12) і (14) та ряду перетворень набуває такого вигляду:

$$
\frac{\Delta T}{T}=\frac{\frac{\delta U+P \delta V}{\Delta U+P \Delta V}-\frac{\delta S}{\Delta S}}{1+\frac{\delta S}{\Delta S}} .
$$

При незначних концентраціях нерівноважних дефектів чи пустот у твердій фазі газогідрату зміни ентропії $\delta S$ і об'єму $\delta V$ нехтовно малі, й рівняння (16) спрощується і набуває вигляду:

$$
\frac{\Delta T}{T}=\frac{\delta U}{\Delta U} .
$$

Нерівноважні дефекти, як правило, впливають і на зміщення тиску фазових переходів. Припустимо, що збільшення об’єму твердої фази газового гідрату у разі переходу «вода - лід» відбувається за рахунок рівності сил стиснення твердого тіла з пустотами і без них в умовах рівноваги, тоді слід прийняти: 
звідси отримаємо:

$$
\frac{\Delta P}{P}=\frac{\delta V}{V} .
$$

$$
(P-\Delta P)(V+\delta V)=P V
$$

Оскільки завжди $\delta V>0$, то під впливом надлишку пустот має спостерігатися зниження тиску фазового переходу, але не більше ніж на $5 \%$, оскільки $\frac{\delta V}{V}<5 \cdot 10^{-2}$ для екстремального випадку тонких плівок. Однак при більш суворому врахуванні впливу пустот на термодинамічні функції $U$ і $S$ за аналогією з обчисленням $\frac{\Delta T}{T}$ отримаємо рівняння:

$$
\frac{\Delta P}{P}=\frac{\frac{T \delta S-\delta U}{T \Delta S-\Delta U}-\frac{\delta V}{\Delta U}}{1+\frac{\delta V}{\Delta V}} .
$$

Якщо прийняти $\delta S$ і $\delta V$ вельми малими, то рівняння (20) спрощується до виразу, що аналогічний рівнянню (17):

$$
\frac{\Delta P}{P}=\frac{\delta U}{\Delta U}
$$

За фізичним змістом рівняння (17) і (21) якісно відображають лише явища релаксації дислокацій, які змінюють внутрішню енергію твердого тіла $\delta U$. Вплив релаксації локацій та інших точкових дефектів, які більш помітно змінюють ентропію $\delta S$ і об'єм $\delta V$, в них не відображено. Необхідно зазначити, що рівняння (17) і (21) можуть бути перетворені до такого вигляду:

$$
\frac{\Delta T}{T}=\frac{\Delta \varepsilon_{1 \rightarrow 2} T}{q T}=\frac{\Delta S_{1 \rightarrow 2}}{\Delta S}=\frac{S_{1 \rightarrow 2}}{\Delta S},
$$

де $\Delta \varepsilon_{1 \rightarrow 2}$ - теплота енергії переходу твердої фази в рідку; $q$ - термодинамічна теплота.

Вираз (22) узагальнює вплив пустот на температуру фазових переходів через зміну ентропії, що якісно узгоджується 3 принципами термодинаміки необоротних процесів, яка враховує виникнення й перетворення ентропії в системі. Рівняння (16) і (20) доцільно використовувати у разі істотної концентрації нерівноважних дефектів у твердій фазі 1, що перетворюється, при аналізі умов прагнення іiі до рівноваги з рідкою фазою 2. Величини $\delta U, \delta S$ і $\delta V$ при впливі тиску мають зрости, порівняно з іншими випадками (наприклад, у формулі (19)), оскільки тиск зменшує рівноважну концентрацію точкових і лінійних мікродефектів у фазі 2 - локацій і дислокацій.

Можливість зниження параметрів $T$ і $P$ на $\Delta T$ і $\Delta P$ відповідно при впливі тільки на стан фази 1 , внаслідок якого відбувається нерівноважне підвищення іiі термодинамічного потенціалу $Z_{1}$ на $\Delta Z$, наведено на рисунку 1 .

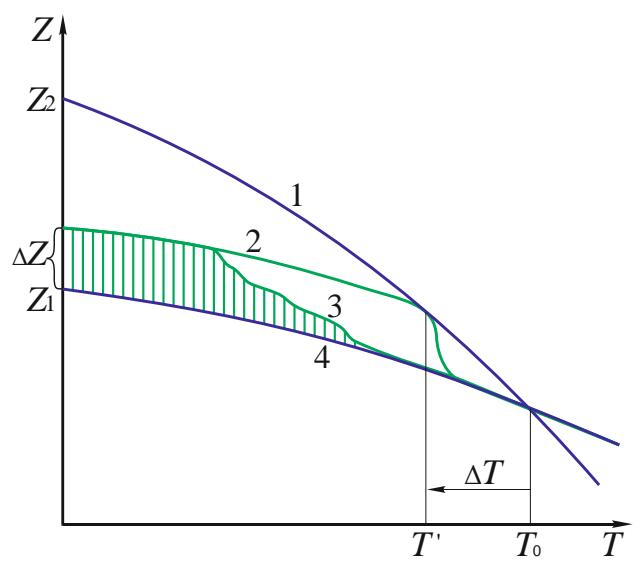

a)

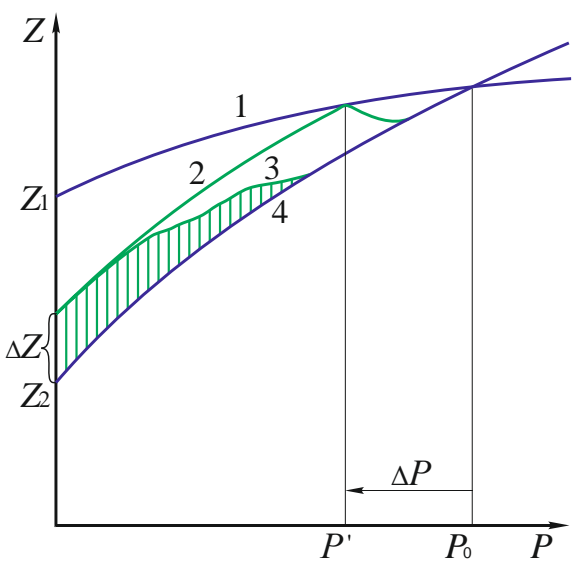

б

Pис. 1. Зміщення температури при $P=$ const (a) і тиску при $T=$ const (б) рівноваги фази 1 i фази 2 при зростанні внутрішньої енергії вихідної фази 1: 1 i 4 криві - зміни термодинамічних потенціалів фаз $Z_{1}$ i $Z_{2}$ залежно від Ti P; 2 і 3 - криві зміни $\Delta Z$ внаслідок релаксаційних явищ,

До релаксаційних явищ можна зарахувати енергію дефектів при поверненні та рекристалізації в умовах повільного і швидкого нагріву або зростання тиску до моменту фазових перетворень. Для одночасного зниження температури і тиску, звісно, необхідне одночасне швидке нагрівання й збільшення тиску. 
Наявність надлишку нерівноважних дефектів у фазі 1, що перетворюється у фазу 2, має також відобразитися у рівнянні Клаузіуса-Клапейрона у зв'язку з доповненням теплового ефекту фазових перетворень $Q$ завжди позитивним тепловим ефектом релаксації дефектів $\delta Q$ :

$$
\frac{\Delta E}{d P}=T \frac{\Delta V}{Q-\delta Q} .
$$

Удосконалене рівняння Клаузіуса-Клапейрона в такому вигляді може застосовуватися для аналізу фазових перетворень у твердих фазах при гідратоутворенні. Шляхом впливу на тверду фазу можна підвищити внутрішню енергію цієї фази, яка при прагненні системи до рівноваги у певних умовах ефективно впливає на процеси фазових перетворень під тиском, а також змінює їх кінетику. Однією 3 можливостей суттєвого підвищення внутрішньої енергії у вихідному перед фазовими перетвореннями стані газогідрату є накопичення в ньому граничних концентрацій різних дефектів та пустот. Енергія релаксації дефектів і є тим термодинамічним стимулом фазових перетворень і твердофазних реакцій, яким можна свідомо керувати.

Висновок. Аналітичними дослідженнями вдосконалено рівняння Клаузіуса-Клапейрона для умов формування газових гідратів, що враховує наявність надлишку нерівноважних дефектів у фазі 1 (лід + газ $\rightarrow$ тверда фаза), що перетворюється у фазу 2 (вода + газ $\rightarrow$ рідка фаза) та має бути також доповнене врахуванням теплового ефекту фазових перетворень завжди позитивним тепловим ефектом релаксації дефектів. Отримане рівняння може застосовуватися для аналізу фазових перетворень у твердих фазах при гідратоутворенні й розкладанні газових гідратів. Однією 3 можливостей суттєвого підвищення внутрішньої енергії у вихідному перед фазовими перетвореннями стані газогідрату є накопичення в ньому граничних концентрацій різних дефектів та пустот. Енергія релаксації дефектів і $\epsilon$ тим термодинамічним стимулом фазових перетворень i твердофазних реакцій, якими можна свідомо керувати.

Представлені результати отримані у межах виконання науково-дослідної роботи ГП-500 «Синтез, оптимізація та параметризація інноваційних технологій освоєння ресурсів газовугільних родовищ».

\section{Список використаної літератури:}

1. Giuliano G. Western Europe and the Long Energy Crisis of the 1970s. / G. Giuliano // Europe in a Globalising World. - 2014. - P. 147-164.

2. Formation of thermal fields by the energy-chemical complex of coal gasification / V.S. Falshtynskyi, R.O. Dychkovskyi, P.B. Saik and other // Naukovyi Visnyk Natsionalnoho Hirnychoho Universytetu. - 2017. № 5. - P. 36-42.

3. Innovative Aspects of Underground Coal Gasification Technology in Mine Conditions / V.Falshtynskyi, P.Saik, V. Lozynskyi and other // Mining of Mineral Deposits. - 2018. - № 12 (2). - P. 68-75.

4. Li J. History and future of the coal and coal chemical industry in China / J.Li, S.Hu // Resources, Conservation and Recycling. - 2017. - № 124. - P. 13-24.

5. Effect of Injection Flow Rate on Product Gas Quality in Underground Coal Gasification (UCG) Based on Laboratory Scale Experiment: Development of Co-Axial UCG System / A.Hamanaka, F.Su, K.Itakura and other // Energies. - 2017. - № 10 (2). - P. 238.

6. Саӥк П. Генераторний газ як альтернатива природному газу / П.Сайк, В.Лозинський // В Матеріали II міжнародної науково-технічної конференції «Газогідратні технології у гірництві, нафтогазовій справі, геотехніці та енергетиці». - Дніпро : Національний гірничий університет, 2016. - С. 34-35.

7. Smith V. Economics of Natural \& Environmental Resources / V.Smith. - London, 2013. - 520 p.

8. Thermodynamic and geomechanical processes research in the development of gas hydrate deposits in the conditions of the Black Sea / V.Bondarenko, K.Sai, K.Prokopenko, D.Zhuravlov // Mining of Mineral Deposits. 2018. - № 12 (2). - P. 104-115.

9. Technological Solutions for the Realization of NGH-Technology for Gas Transportation and Storage in Gas Hydrate Form / M.Pedchenko, L.Pedchenko, T.Nesterenko, A.Dyczko // Solid State Phenomena - 2018. - № 277. - P. 123-136.

10. Патент RU № 2270053. Способ получения газовых гидратов / В.П. Коверда, А.В. Решетников, М.3. Файзуллин. - Бюл. № 21. - 2006.

11. Пат. UA № 102659. Спосіб отримання газових гідратів з газової суміші дегазаційної свердловини / О.В. Агафонов, О.В. Сніковський, І.О. Дєдіч та ін. - Бюл. № 14. - 2013.

12. Melnikov V. Cryodiversity: the World of Cold on the Earth and in the Solar System / V.Melnikov, V.Gennadinik // Philosophy and Cosmology. - 2018. - № 20. - P. 43-54.

13. Pedchenko M. Analysis of gas hydrate deposits development by applying elements of hydraulic borehole mining technology / M.Pedchenko, L.Pedchenko // Mining of Mineral Deposits. - 2017. - № 11 (2). - P. 52-58.

14. Дядин Ю.А. Газовые гидраты / Ю.А. Дядин, А.Л. Гущзин // Соросовский образовательный журнал. - 1998. № 3. - C. 55-64.

15. Пригожин И. Введение в термодинамику необратимых процессов / И.Пригожин. - Ижевск : НИЦ «Регулярная и хаотическая динамика», 2001. - 160 с.

16. Пригожин И. Биологический порядок, структура и неустойчивости / И.Пригожин, Дж.Николис // Успехи физических наук. - 1973. - № 109 (3). - С. 517-527.

17. Хаазе P. Термодинамика необратимых процессов / Р.Хаазе. - М. : Мир, 1967. - 544 с

18. Бюргер М.Д. Фазовые переходы / М.Д. Бюргер // Кристаллография. - 1971. - № 16 (6). - С. 10-84. 
19. Светкина Е.Ю. Температурные эффекты при вибронагружении / Е.Ю. Светкина, В.П. Франчук // Науковий вісник Національного гірничого університету. - 2003. - № 1. - С. 70-72.

\section{References:}

1. Giuliano, G. (2014), «Western Europe and the Long Energy Crisis of the 1970s», Europe in a Globalising World, pp. 147-164.

2. Falshtynskyi, V.S., Dychkovskyi, R.O., Saik, P.B. et al. (2017), «Formation of thermal fields by the energy-chemical complex of coal gasification», Naukovyi Visnyk Natsionalnoho Hirnychoho Universytetu, No. 5, pp. 36-42.

3. Falshtynskyi, V.S., Saik P., Lozynskyi,V. et al. (2018), «Innovative Aspects of Underground Coal Gasification Technology in Mine Conditions», Mining of Mineral Deposits, No. 12 (2), pp. 68-75.

4. $\mathrm{Li}, \mathrm{J}$. and $\mathrm{Hu}, \mathrm{S}$. (2017), «History and future of the coal and coal chemical industry in China», Resources, Conservation and Recycling, No. 124, pp. 13-24.

5. Hamanaka, A., Su, F., Itakura, K. et al. (2017), «Effect of Injection Flow Rate on Product Gas Quality in Underground Coal Gasification (UCG) Based on Laboratory Scale Experiment: Development of Co-Axial UCG System», Energies, No. 10 (2), pp. 238.

6. Sai'k, P. and Lozyns'kyj, V. (2016), «Generatornyj gaz jak al'ternatyva pryrodnomu gazu», V Materialy II mizhnarodnoi' naukovo-tehnichnoi' konferencii' "Gazogidratni tehnologii' u girnyctvi, naftogazovij spravi, geotehnici ta energetyci», Nacional'nyj girnychyj universytet, Dnipro, pp. 34-35.

7. Smith, V. (2013), Economics of Natural \& Environmental Resources, London, 520 p.

8. Bondarenko, V., Sai, K., Prokopenko, K. and Zhuravlov, D. (2018), «Thermodynamic and geomechanical processes research in the development of gas hydrate deposits in the conditions of the Black Sea», Mining of Mineral Deposits, No. 12 (2), pp. 104-115.

9. Pedchenko, M., Pedchenko, L., Nesterenko, T. and Dyczko, A. (2018), «Technological Solutions for the Realization of NGH-Technology for Gas Transportation and Storage in Gas Hydrate Form», Solid State Phenomena, No. 277, pp. 123 - 136.

10. Koverda, V.P, Reshetnikov, A.V. and Faizullin, M.Z. (2006), «Sposob polucheniya gazovykh gidratov», Patent $R U$, No. 2270053, Bjuleten' No. 21.

11. Agafonov, O.V., Snikovs'kyj, O.V. and Djedich, I.O. (2013), «Sposib otrymannja gazovyh gidrativ z gazovoi' sumishi degazacijnoi' sverdlovyny», Patent UA, No. 102659, Bjuleten' No 14.

12. Melnikov, V. and Gennadinik, V. (2018), «Cryodiversity: the World of Cold on the Earth and in the Solar System», Philosophy and Cosmology, No. 20, pp. 43-54.

13. Pedchenko, M. and Pedchenko, L. (2017), «Analysis of gas hydrate deposits development by applying elements of hydraulic borehole mining technology», Mining of Mineral Deposits, No. 11 (2), pp. 52-58.

14. Dyadin, Yu.A. and Gushchin, A.L. (1998), «Gazovye gidraty», Sorosovskii obrazovatel'nyi zhurnal, No. 3, pp. 55-64.

15. Prigozhin, I. (2001), Vvedenie v termodinamiku neobratimykh protsessov, NICz «Regulyarnaya i khaoticheskaya dinamika», Izhevsk, $160 \mathrm{p}$.

16. Prigozhin, I. and Nikolis, Dzh. (1973), «Biologicheskii poryadok, struktura i neustoichivosti», Uspekhi fizicheskikh nauk, No. 109 (3), pp. 517-527.

17. Khaaze, R. (1967), Termodinamika neobratimykh proczessov, Mir, Moskva, 544 p.

18. Byurger, M.D. (1971), «Fazovye perekhody», Kristallografiya, No. 16 (6), pp. 10-84.

19. Svetkina, E.Yu. and Franchuk, V.P. (2003), «Temperaturnye effekty pri vibronagruzhenii», Naukovyi Visnyk Natsionalnoho Hirnychoho Universytetu, No. 1, pp. 70-72.

Сай Катерина Сергіївна - кандидат технічних наук, доцент кафедри гірничої інженерії та освіти Національного технічного університету «Дніпровська політехніка».

Наукові інтереси:

- розробка родовищ корисних копалин;

- газогідратні технології.

Саїк Павло Богданович - кандидат технічних наук, доцент кафедри гірничої інженерії та освіти Національного технічного університету «Дніпровська політехніка».

Наукові інтереси:

- геотехнології гірництва;

- підземна газифікація вугілля.

Лозинський Василь Григорович - кандидат технічних наук, доцент кафедри гірничої інженерії та освіти Національного технічного університету «Дніпровська політехніка».

Наукові інтереси:

- геотехнології гірництва;

- підземна газифікація вугілля.

Петльований Михайло Володимирович - кандидат технічних наук, доцент кафедри гірничої інженерії та освіти Національного технічного університету «Дніпровська політехніка».

Наукові інтереси:

- розробка родовищ корисних копалин;

- закладка виробленого простору. 